\title{
Identification of elite aspen clones in the experimental plantation in the North- West of Russia
}

\author{
(C) Anatoly V. Zhigunov ${ }^{1 *}$, Dmitrii A. Shabunin ${ }^{2}$, Olesia Yu. Butenko², \\ Marina V. Lebedeva ${ }^{1}$
}

${ }^{1}$ Saint Petersburg State Forest Technical University, St. Petersburg, 194021 Russia, Institutskiy per., 5.

${ }^{2}$ St. Petersburg Forestry Research Institute, St. Petersburg, 194021 Russia, Institutskiy pr., 21.

*Corresponding author (e-mail: a.zhigunov@bk.ru, +79213923119)

Identification of elite aspen clones in the experimental plantation in the North-West of Russia A.V. Zhigunov, D.A. Shabunin, O.Yu. Butenko, M.V. Lebedeva (Saint Petersburg State Forest Technical University, Saint Petersburg Forestry Research Institute)

In 2001-2006 several experimental aspen (Populus tremula L.) plantations were established in the North-West of Russia (Leningrad region). In vitro propagated elite aspen clones from the Kostroma Forest Research Station were used as the planting stock for plantations. Periodic observations of tree growth and development were carried out during the entire period of their growth. However, the planting plans of some experimental plantations were lost, which made it impossible to identify the genetic affiliation of the trees. To restore the lost planting plan at the site No. 6 in the 49th quarter of the Druzhnoselskoye district forestry of the Gatchina central forestry microsatellite ISSR analysis were used. In total, eight ISSR primers were examined. Only three of them (HB12, M12C, M10) gave a well-read and fairly complete electrophoretic distribution of amplicons. In this case primers HB12 and M14 allowed only two groups of plants distinguishing, and the primer M12C allowed distinguishing of three groups. Primer M12C allowed 20 loci analyzing, 15 of which turned out to be polymorphic. Thus, the application of methods of molecular genetics made it possible to split the entire set of plants into three groups. Repeated visual inspections of plants allowed minor morphological differences between trees revealing, which confirmed the correctness of the selection of groups by molecular markers. The revealed groups of trees differed also in growth. The best of them grow at the level of natural aspen coppice, and recently there has been a tendency to accelerate their growth. These groups are recommended for cultivation in the north-west of Russia.

Keywords: Aspen, elite clones, molecular markers, ISSR, clonal plantations 
Идентификация элитных клонов осины, выращиваемых в опытных лесных культурах в северо-западном регионе России

\section{А.В. Жигунов, Д.А. Шабунин, О.Ю. Бутенко, М.В. Лебедева}

В 2001-2006 гг. в Ленинградской области было заложено несколько опытных участков лесных культур осины (Populus tremula L.) из посадочного материала, полученного в результате микроклонального размножения в условиях in vitro элитных клонов этой породы, произрастающих в Костромской области. За ростом и развитием посадок велись периодические наблюдения, однако вследствие административных реорганизаций первоначальные схемы размещения рамет на участках были утеряны, в результате определить генетическую принадлежность растений в опытных культурах было невозможно. Для восстановления утраченного плана посадок на участке № 6 в 49 квартале Дружносельского участкового лесничества Гатчинского лесничества были использованы молекулярные межмикросателитные маркеры (ISSR). Всего было исследовано восемь праймеров. Только три из них (НВ12, М12C, М10) давали хорошо читаемое и достаточно полное электрофоретическое распределение ампликонов. При этом праймеры НВ12 и М14 позволяли различить только две группы растений, а праймер М12C три группы. Праймер М12С позволял анализировать 20 локусов, 15 из которых оказались полиморфными. Таким образом, применение методов молекулярной генетики позволило разбить всю совокупность растений на участке на три группы. Повторные визуальные обследования растений позволили выявить незначительные морфологические отличия между деревьями, которые подтверждали правильность выделения групп по молекулярным маркерам. Выявленные группы деревьев отличались также по темпам роста. Лучшие из них растут на уровне естественной корневой поросли осины, и в последнее время наметилась тенденция ускорения их роста. Эти группы рекомендованы для выращивания на северо-западе России.

Ключевые слова: осина, элитные клоны, молекулярные маркеры, ISSR, клоновые посадки

'Жигунов Анатолий Васильевич - профессор кафедры почвоведения и лесных культур, доктор с.-х. наук, профессор

${ }^{2}$ Шабунин Дмитрий Александрович - ведущий научный сотрудник НИО селекции, воспроизводства и химического ухода за лесом, канд. биол. наук

${ }^{2}$ Бутенко Олеся Юрьевна - старший научный сотрудник НИО селекции, воспроизводства и химического ухода за лесом, канд. с.-х. наук

E-mail: din_don@bk.ru

1Лебедева Марина Валерьевна - ассистент кафедры почвоведения и лесных культур E-mail: marilistik@mail.ru

${ }^{1}$ ФГБОУ ВО «Санкт-Петербургский государственный лесотехнический университет имени С.М. Кирова»

194021 Санкт-Петербург, Институтский пер., 5

Телефон: 8 (812) 670-93-17

E-mail: public@spbftu.ru

${ }^{2}$ ФБУ «Санкт-Петербургский научно-исследовательский институт лесного хозяйства», 194021 Санкт-Петербург, Институтский пр., 21

Телефон: (812) 552-80-26

E-mail: mail@spb-niilh.ru 